\title{
Design of Online Learning Platform for 'Computer Courses'
}

\author{
Wang Xiaogang ${ }^{1,}$,, Yan Fan ${ }^{2, b}$ \\ ${ }^{1}$ Room 455,XiongChu Street,HongShan District, Wuhan City, Hubei Province, China \\ ${ }^{2}$ Room 455,XiongChu Street,HongShan District, Wuhan City, Hubei Province, China \\ abeloved8888@126.com, ${ }^{\mathrm{b}}$ 278896179@qq.com
}

\begin{abstract}
Keywords: E-learning, Online learning, Computer Learning Platform
Abstract. The architecture and function of the system are analyzed roundly and a comprehensive solution of online learning platform is put forward, which may help to solve a series of problems such as low efficiency, poor practicality, and non-ideal effect in remote teaching and so on being in the present network learning system. Online learning platform which includes the whole teaching links and its management process with self-learning and intelligence is introduced in order to raise further teaching effects and efficiency. Online learning platform is an important supplement to classroom teaching. The design and development of online learning platform is an important subject for computer curriculum reform. Besides, it plays an important role in enhancing the students' learning efficiency, developing their interest in learning, and stimulating their enthusiasm for learning.
\end{abstract}

\section{Foreword}

Along with the development of information technology and digital resources of teaching, the traditional teaching mode for computer courses is being impacted by information technology. The traditional teaching mode of 'teaching-demonstration-operation on computers' with teacher dominated in classrooms can not yet meet the students' demand for knowledge acquisition in the information era. This rigid teaching mode is unable to arouse the students' enthusiasm for learning. The traditional teaching mode has to be improved. At the same time, other choices of teaching methods should also be considered. A diversification of teaching mode can better contribute to the improvement of teaching quality and cultivation of the students' occupational skills and professionalism. In order to complete this mission, only relying on traditional face-to-face type of education is impracticable [1].

As an extension and complement for classroom teaching, the online teaching platform breaks the temporal and geographical restrictions of classroom teaching under the rapid development of computer, multimedia, and internet technologies. It has become one of the development directions of teaching mode with the advantages of making full use of internet technology and digital teaching resources in creating an interactive, personalized, dynamic, and real-time online learning platform for students. As the development of both the teachers and students' skills in computer operation and the internet environment supported by the construction of digital school, the application of online teaching platform is ripe in time.

\section{Organizational structure of the online learning platform}

With the rapid development of internet technology, the traditional teaching mode based on behaviorism and cognitivism can not yet meet the new demand of online teaching [2]. In the meantime, the online teaching mode based on constructivism is becoming a new focus for researchers [3]. The online learning platform is a good supplement to classroom teaching as a teaching and learning system oriented to both teachers and students on the basis of campus network. In the online platform, teachers are responsible for maintaining and managing the contents while students are the users. The students are allowed to conduct online learning, online testing, 
homework submission, and online discussion etc., while the teachers use the platform to obtain teaching resources, assign and correct students' homework, and make use of the analytical and statistical functions of the platform to keep abreast of students' learning progress. The organizational structure of the platform is shown in Figure 1.

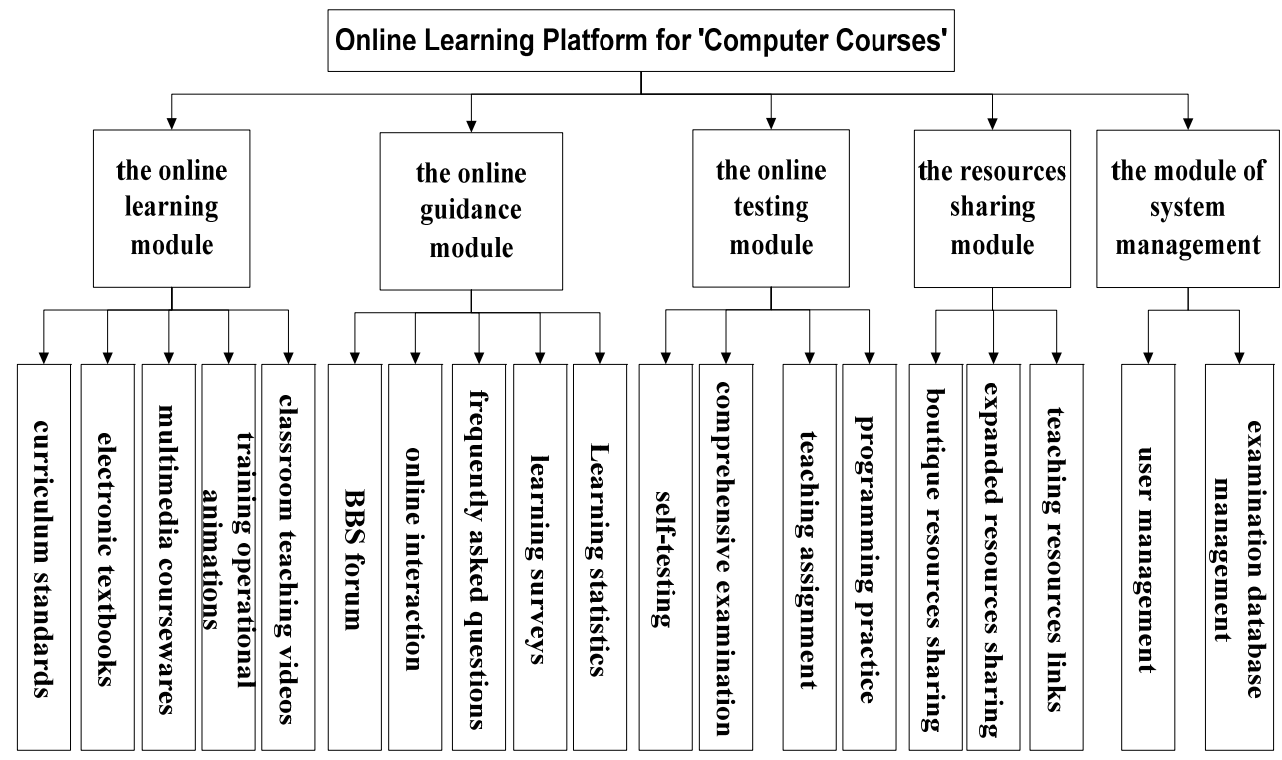

Fig. 1 The organizational structure of the platform

The online learning module provides a large quantity of learning resources including curriculum standards, electronic textbooks, multimedia coursewares, training operational animations, and classroom teaching videos. By using the resources, the students can do pre-class and after-school reviews effectively, and understand further the knowledge taught by teachers at class.

The online guidance module includes BBS forum, online interaction, frequently asked questions, and learning surveys and statistics. BBS forum is the main module where teachers provide guidance to students. Students can get teachers' support by posting questions at the forum to solve their problems encountered in learning, and exchange learning experiences with other students. The online interaction module creates an interactive and real-time forum between teachers and students, where the teachers answer students' questions online. The frequently asked questions are mistakes or problems that the students frequently make or encounter which are summarized by teachers according to their teaching experiences. When encountering these problems, students can get the answers directly by querying the database instead of waiting for teacher's answers. Learning survey is designed for teachers where they can understand the student's learning satisfaction and obtain other information through distributing questionnaires to them online. Through learning statistics, the information about each student's login address, duration, content browsed, and posts can be obtained for tracking their learning status.

The online testing is composed of two sections, i.e., testing section and homework section. The testing section comprises self-testing module and comprehensive examination module; the homework section includes teaching assignment and programming practice. In the self-testing module, students can test the outcomes of self learning after completing each task and understand their mastery of knowledge so as to take targeted measures. The comprehensive examination module provides comprehensive simulation exercises for students to test their learning effectiveness. The teaching assignment module is convenient for teachers to assign homework for the students, while the students can complete and submit their homework in this module. Through the 
programming practice module, teachers can regularly publish real project tasks to students who are required to complete them within specified time. By doing so, the students' practical abilities will be trained.

The resources sharing module is composed of boutique resources sharing, expanded resources sharing, and teaching resources links. The boutique resources are mainly collected and uploaded by teachers. They can be professional works with a certain degree of difficulty or the outstanding works of the students who have graduated. They can be used as the teachers' teaching resources or students' learning resources for self-improvement. The expanded resources are mainly collected by students and uploaded after teacher's approval as learning resources to broaden their horizons. The teaching resource links are some links of internet resources such as websites, forums etc. contributed to enriching the students' learning subjects.

The module of system management comprises user management and examination database management. The platform manager module is responsible for user management i.e. management of the registered users. Students and teachers have different designed roles and access authorities. Each registered user can manage and revise their own information. The user management module supports records of operational logs of the platform, which allows users to view but not modify the records. The operational log records each user's entry information such as login address and duration, as well as the information about their operations such as the information browsed, content posted, and resources shared. The users have the authority to only check their own operational logs while the manager has the authority to check the logs of all users. The examination database is designed especially for teachers. The examination database management refers to the maintenance of exams in self-testing module and comprehensive examination module such as adding, revising and deleting operations.

3. Realization of online learning platform

The platform was tested and applied by Hubei Communications Technical College in the second half of 2013. It runs rather stable and has a good performance as expected. Its main interface is showed in Figure 2.

\section{Characteristics of the online learning platform}

3.1 Setting real projects and enriching practical teaching

In the online platform, besides the usual teaching resources such as teacher handout, lesson plans, electronic textbooks, and classroom video, there are also real projects which are selected carefully by professional teachers and regularly published. There are two main types of such projects:

\section{1) Cases of real projects}

They are real cases collected by professional teachers in their activities of project development, including both the cases of the projects already developed and those being developed. The students are organized spontaneously into discussion groups to bid the projects. The teacher will then distribute the projects to various groups following a principle of fairness and justice. Afterwards, the student groups must finish the development of projects or propose constructive recommendations for difficult ones within specified time. Finally, the teachers give scores to the student groups based on their degrees of completion or the feasibility of their recommendations. The scores will be included in the overall performances of the students for the course. For example, in the course of 'Fundamentals of Computer Application', the teachers will publish the task of revision of the multimedia courseware as a project in the programming practice module of the online learning platform. After receiving the project, the students will revise and improve the software. As the students are the end viewer of the multimedia courseware, the software revised by them will be 
easier to accept and understand and more likely to be applied in practice.

2) Real exams of skill competition

They are real exams of computer competition or software programming contest introduced with new technologies or standards in related industries and enterprises that are closest to the students' future jobs. The embedding of practices into students' courses will not only improve their professional skills but also increase their confidences in employment by showing them in advance the tasks and work to be faced in the future. In particular, the real exams of the software programming contest typically have some fun and the students will not be bored, by which the students' enthusiasm for learning will be aroused.

\subsection{Applying technology to promote the activity for learning}

Related technology is applied in the online learning platform to enhance the students' activity for learning by regularly reminding them of learning. Most online learning platforms are able to record the students' login duration which is used to judge their attitudes towards learning. However, a large number of students minimize the platform web page after logging in and play games or watch films instead of learning.

The platform has a function of asking a question once in a certain period of time (set according to the time length of a course). When the time is up, a multiple choice question related to the content browsed by the student is popped up automatically from the database. If the students give wrong answers to more than two questions, the login duration for that time will be invalid. Investigation shows that after including in the reminding function, the students have made significant progress in learning.

3.3 Conducting real time interaction between teachers and students to arouse the students' enthusiasm for learning

Most current online teaching platforms support the teaching mode based on courses [4]. However, the modern online teaching platform should not only be an extension of classroom teaching, but also build connections between the learners and the learning resources. A real time interaction will be most effective, for example, the formation of a virtual learning community with two-way exchanges [5].

Besides the BBS forum for communications between teachers and students, the online learning platform also has a module for real time interaction between the teacher and students. Although BBS forum can be used in interaction between teachers and students, since teachers cannot be always online, their answers to students' questions will be delayed. It was observed that such asynchronous interaction frustrates the students' learning motivation to a certain extent. After several times of failure in getting the teacher's answer in time, the number of questions proposed by students and the degree of their participation decrease significantly, some students will even no longer propose questions. In order to solve this problem, it is indispensable to include a real time interaction module in the platform. The teachers conduct real time online interactions with students regularly and require them to participate in group discussion. The topics for discussion could be difficulties that students encounter in learning or the problems arise in practice. Teachers select the topic for discussion each time based on the universality of the questions. The students then conduct brainstorming discussions and provide referential suggestions eventually. While guiding the discussions, teachers also have to record the degree of participation of each group which will be included in students' overall score of the course.

3.4 Tracking teacher's logging trajectory and recording the teaching workload to stimulate their enthusiasm for teaching

The online learning platform builds an effective environment for students to learn after class 
but brings no small extra-curricular teaching workload for teachers. To make the online learning platform welcomed by students and fulfill its role in assisting student learning, the resources on the platform have to be diversified. In order to achieve this, teachers have to contribute more time in addition to providing support in the real time online interactions regularly, answering their questions in BBS forum, and publishing practical projects in the project module. Such work has to be finished at time out of classes by the teachers. Then how to calculate the workload of teachers for supporting the platform? With different online durations, the teachers may publish resources and information of different qualities. Then how to calculate their contributions? The difficulty of calculating teachers' workload has always been a barrier for promoting the use of the online learning platform.

To solve this, the operational log module is designed for the online learning platform. Through its tacking and recording function, a full understanding of the teacher's teaching process is obtained. Thus the teacher's workload can be calculated according to their online durations and the quality of published resources and information to ensure their enthusiasm for online teaching. In the meantime, the teacher's contribution in collection and publication of resources are also included in the calculation of workload. Since the teachers are responsible for the development, improvement and maintenance of the platform, they will be benefited from the enrichment of the platform for a long run, which will also facilitate the formation of a virtuous circle of the platform.

\section{Conclusion}

The online learning platform is an effective supplement to classroom teaching. It compensates the disadvantage of the traditional teaching mode that pays extra emphasis to knowledge teaching while ignoring ability training. Through the online testing module and programming practice module of the online learning platform, students' problem analyzing and solving abilities are improved. The real time interaction module of the platform shortens the distance between teachers and students, and make the students more active in proposing questions. The learning mode breaking the temporal and geographic limits makes the students more free and convenient in learning. The rich and diversified teaching resources arouse their enthusiasm in learning and make them spend more free time in learning.

\section{References}

[1]Huang Xinbing,Wang Dongjiang and Dai Jinrong:The concept of promoting vocational education with great development by modern distance education(in Chinese). submitted to Journal of Vocational and Technical Education(2007).

[2]Shen Jun, Gu Guanqun:Interactive architecture model for network teaching. submitted to Journal of Southeast University(2002).

[3]Song Junfeng,ZhangWeiming,XiaoWeidong,etal:Reserchon ontology based information retrieval model. submitted to Journal of Nanjing University (2005).

[4] Nada D, Brenda B:Online learning: concepts, strategies and application. edtied by Prentice Hall, New Jersey(2004).

[5] Yu Shengquan, He Kekang: Architecture and function of the network teaching platform. submitted to Journal of China Education Technology(2001). 